\title{
The Relationship between the Metabolic Syndrome and the Risk of Obstructive Sleep Apnea Evaluated by STOP-Bang Questionnaire in Professional Drivers in Shahroud, Iran, in 2020: A Case-Control Study
}

\author{
Mohammad Hossein Ebrahimi', Shayesteh Jahanfar ${ }^{2, *}$, Mina Shayestefar ${ }^{3, *}$ \\ 'Environmental and Occupational Health Research Center, Shahroud University of Medical Sciences, Shahroud, Iran; ${ }^{2}$ MPH Program, School of Health Sciences, \\ Central Michigan University, MI, USA; ${ }^{3}$ School of Allied Medical Sciences, Semnan University of Medical Sciences, Semnan, Iran
}

Background: The present study was conducted to investigate the relationship between metabolic syndrome and the risk of respiratory and sleep disorders in professional drivers.

Methods: This case-control study was conducted on professional drivers in Shahroud, Iran. The snoring, tiredness during daytime, observed apnea, high blood pressure, body mass index, age, neck circumference, gender (STOP-Bang) questionnaire was first used to assess obstructive sleep apnea (OSA). Then, based on the questionnaire scores, the participants were divided into two groups: those with and those without OSA. The relationship between this disorder and metabolic syndrome was then studied. Data were analyzed using descriptive and analytical tests $(P<0.05)$.

Results: Based on the STOP-Bang questionnaire, 214 drivers with a high risk of OSA and 214 drivers with low risk were recruited for the study. According to the Adult Treatment Panel III criteria, 204 drivers (47.7\%) had metabolic syndrome. There was a significant relationship between driver's license class and the risk of OSA. Metabolic syndrome components including fasting blood sugar, triglycerides, and hypertension, but not high-density lipoprotein cholesterol, were able to predict OSA in the professional drivers.

Conclusion: Given the high prevalence of metabolic syndrome and OSA, especially in drivers of high risk who may spend long hours transporting good and operating passenger vehicles, screening and treating these disorders are crucial in this part of the population. The researchers recommend holding regular training sessions about these disorders for professional drivers.

Key words: Obstructive sleep apnea, Metabolic syndrome, Drivers
Received October 13, 2020

Reviewed December 5, 2020

Accepted January 20, 2021

*Corresponding author

Mina Shayestefar

https://orcid.org/0000-0002-9388-1622

School of Allied Medical Sciences, Semnan University of Medical Sciences, Semnan 35147-99442, Iran

Tel: +98-33614637

Fax: +98-33614664

E-mail:m.shayestefar@semums.ac.ir

"Current affiliation: Department of Public Health and Community Medicine, Tufts University School of Medicine, Boston, MA, USA

\section{INTRODUCTION}

Global traffic accident mortality statistics show that accidents are a major challenge in public health for all age groups. ${ }^{1}$ Traffic accidents cause more than five million deaths around the world every year, ${ }^{2}$ and this rate is expected to increase to 8.5 million by $2020 .^{3}$ Traffic accidents are the third most common (10.3\%) cause of mortality after cardiovascular diseases (44.1\%) and neoplasms (15.9\%) in Iran. ${ }^{4}$ The World Health Organization has reported the estimated annual number of road traffic deaths in Iran as $24,896 .^{5}$

A significant number of Iranian drivers have communicated their poor sleep quality, sleepiness while driving, and sleep-disordered breathing (obstructive sleep apnea [OSA]). Some of the factors

Copyright @ 2021 Korean Society for the Study of Obesity

(a) This is an Open Access article distributed under the terms of the Creative Commons Attribution Non-Commercial License (https://creativecommons.org/licenses/by-nc/4.o/) which permits unrestricted non-commercial use, distribution, and reproduction in any medium, provided the original work is properly cited. 
that increase the prevalence of road traffic accidents include snoring, smoking, driving hours during the day, excessive sleepiness, and perhaps also apnea. ${ }^{6} \mathrm{~A}$ shorter sleep duration is inversely associated with the risk of metabolic syndrome (MetS). ${ }^{7}$

MetS or syndrome $\mathrm{X}$ is a cluster of conditions commonly associated with abdominal obesity, hypertension, dyslipidemia, hyperglycemia, and possibly insulin resistance. ${ }^{8}$ Currently, this syndrome is considered a threat to the public health of the community because it increases the risk of cardiovascular diseases, type 2 diabetes, and mortality. ${ }^{8-11}$ Although there are several definitions for the diagnosis of MetS, the most applicable clinical diagnosis is made using the Adult Treatment Panel (ATP) III criteria. According to this definition, the patient should have at least three cardiovascular risk factors simultaneously. ${ }^{12}$

The prevalence of this syndrome has increased in recent years. The literature suggests that the prevalence of MetS ranges from $12.8 \%$ to $41.7 \%$ in different countries, while it has been reported as $22 \%-31 \%$ in Iran. ${ }^{13,14}$ Many factors, such as lifestyle (physical activity and diet) and socioeconomic status, play significant roles in the development of MetS. ${ }^{15-17}$

Sleep is a vital biological process that is essential for growth since the stage of prenatal development. Sleep has a bilateral interaction with the cardiovascular, ${ }^{18,19}$ respiratory, ${ }^{20}$ and endocrine systems..$^{21,22}$ Poor sleep quality is associated with a high risk of cognitive impairment, poor academic performance, behavioral disorders, traffic accidents, and chronic conditions such as obesity. ${ }^{23}$ Obstructive sleep apnea-hypopnea syndrome (OSAS) is a disorder characterized by repetitive upper airway collapse and oxygen desaturation during sleep. The syndrome is estimated to affect $2 \%-4 \%$ of the population. ${ }^{24}$ Common complaints of patients with OSAS include severe sleepiness during the day, fatigue, irritability, ${ }^{25}$ depression, and cognitive impairment. ${ }^{26}$

Due to its high prevalence, OSAS affects the entire general population (almost $4 \%$ of men and $2 \%$ of women) and also has negative health effects such as cardiovascular morbidity and mortality, neuropsychiatric changes, and poor quality of life. ${ }^{27}$ Sufficient sleep is essential for physical and mental health. Nonetheless, many adults suffer from multiple problems associated with the lack of or poor sleep, including cognitive impairment and behavioral problems, obesity, and the risk of life-threatening accidents. Detecting and treating sleep problems is indispensable to the promotion of adults' health. $^{27}$

Due to their particular work conditions, drivers are more susceptible to diseases, especially sleep disorders as well as MetS and its complications. Moreover, traffic accidents, which are the third leading cause of death in Iran, are a serious threat to the health of drivers and consequently to other people's lives. Considering the risky profession of drivers, their impactful role in the health of others, and also the lack of information on this subject in Shahroud, the present study was conducted to investigate MetS and the risk of OSA in drivers in Shahroud and find the relationship between them.

\section{METHODS}

\section{Study design and participants}

This case-control study was conducted on some of the professional drivers of Shahroud. Professional drivers are responsible for transporting almost all passengers and road freight under the supervision of the Iran Road Maintenance \& Transportation Organization. Three types of driver's license classes related to the types of cars driven exist in Iran: a class 1 certificate is a license for driving trucks heavier than 6 tons and passenger cars carrying more than 26 people, a class 2 certificate authorizes the driving of trucks weighing up to 6 tons and passenger cars with capacities of up to 26 people, and a class 3 certificate is the most common license for driving motorcars with a maximum total weight of 3.5 tons and $<10$ passengers, depending on the type of the vehicle.

The participants were briefed on the study objectives and then signed informed consent forms, which indicated the risks, benefits, and voluntary decision of participation in this study. The research protocol was approved by Shahroud University of Medical Sciences with the ethics code IR.SHMU.REC.1395.174. The snoring, tiredness during daytime, observed apnea, high blood pressure, body mass index (BMI), age, neck circumference, gender (STOPBang) questionnaire (SBQ) was used to evaluate sleep disorders in the participants.

Since the study was case-controlled, the prevalence reported for MetS in the study by Kiełbasa et al. ${ }^{28}$ was used to determine the sample size for assessing sleep disorders and its relationship with MetS. In their study, the prevalence of sleep disorders was 
$75 \%$ in the subjects with MetS and 62\% in the normal subjects. The SBQ was also used in their study, just like in the present study. Finally, the sample size for this study was estimated as 214 per group.

From the 948 professional drivers presenting to the Kasra occupational clinic for their annual physical and laboratory examinations, 428 drivers with low and high risks of OSA were selected for the two groups. The study by Kiełbasa et al. ${ }^{28}$ was used to calculate the number of participants for measuring sleep disorders and their relationship to MetS. The inclusion criteria consisted of participants' easier accessibility and consent to participate in the study. The inclusion criterion for the first group was having a low risk of OSA based on the SBQ and for the second group, the criterion was having a high risk of OSA. The participants were then divided into two groups of 214. Their age range was 22-69 years (mean, $44.18 \pm 11.57$ years).

\section{Data collection, analysis, and statistical analysis}

The SBQ is a questionnaire to screen for OSA, which was distributed among the participants. It consists of eight items, including snoring, tiredness, observed apnea, high blood pressure, BMI more than $30 \mathrm{~kg} / \mathrm{m}^{2}$, age older than 50 years, neck circumference more than $40 \mathrm{~cm}$, and gender. Risk of OSA was the independent variable examined in this study, and the MetS was the dependent variable. The relationship between these variables and the likelihood of joining the sleep disorder group was evaluated. Adjustments were made for confounding variables including age, education, household size, income, socioeconomic status, and smoking status.

The paraclinical data obtained included low-density lipoprotein (LDL) cholesterol, high-density lipoprotein (HDL) cholesterol, triglycerides (TG), fasting blood sugar (FBS), and blood pressure. Blood pressure was tested with a single manometer for all the participants, from their left arms, in upright seated position, with the legs uncrossed. Pars Azmun kits (Karaj, Iran) were used for laboratory tests.

To estimate the prevalence of MetS, data including waist circumference, TG, HDL cholesterol, FBS and hypertension were evaluated. MetS is diagnosed based on three or more criteria of the ATP III, including abdominal obesity (waist circumference more than $102 \mathrm{~cm}$ in men and more than $88 \mathrm{~cm}$ in women), $\mathrm{TG} \geq 150 \mathrm{mg}$, HDL cholesterol $<40 \mathrm{mg} / \mathrm{dL}$ in men and HDL cholesterol $<50 \mathrm{mg} / \mathrm{dL}$ in women, blood pressure $\geq 130 / 85 \mathrm{mmHg}$, and fasting blood glucose $\geq 110 \mathrm{mg} / \mathrm{dL}$.

Blood samples were taken from all participants after 12 hours of fasting, and the serums were sent to the laboratory of Razavi Clinic, affiliated with Shahroud University of Medical Sciences, for LDL cholesterol, HDL cholesterol, total cholesterol, TG, and blood glucose testing. All participants were examined with the same method. Then, the relationship between MetS and the risk of OSA was investigated in the drivers of Shahroud. All of the tests were twotailed, and the level of statistical significance was set at 0.05 by IBM SPSS version 23 (IBM Corp., Armonk, NY, USA).

\section{Questionnaire design}

\section{STOP-Bang questionnaire}

The SBQ includes eight items: snoring, tiredness, observed apnea, high blood pressure, BMI more than $30 \mathrm{~kg} / \mathrm{m}^{2}$, age older than 50 years, neck circumference more than $40 \mathrm{~cm}$, and male gender. The questionnaire predicts the likelihood of OSA and respiratory complications after surgery. ${ }^{19}$ The SBQ items are dichotomous (yes/no). One point is given to a "yes" answer and no points are given to the answer "no". Having three or more positive answers indicates a high risk of OSA, and having less than three positive answers shows a low risk of OSA. ${ }^{19}$

To examine the validity and reliability of the Persian version of the SBQ, in 2015, Sadeghniiat-Haghighi et al. ${ }^{29}$ used the tool on 603 patients admitted to sleep clinics and performed polysomnography on them. In the analysis of reliability, 124 patients were found to have similar scores in STOP, and 130 patients suffered from the same level of OSA. According to the polysomnography of 438 patients, $20.4 \%$ had mild OSA, $18.9 \%$ had moderate OSA, and $33.3 \%$ had severe OSA. Eventually, it was concluded that the Persian version of the questionnaire serves the same function as the original one. $^{29}$

\section{RESULTS}

By administering the SBQ, we selected 214 drivers $(22.57 \%)$ as high-risk for OSA and 214 drivers (22.57\%) as low-risk for OSA 
from 948 total referred professional drivers. According to the ATP III criteria, 204 drivers (47.7\%) had MetS out of 428 participants. Among the SBQ scores of the 428 drivers, the mean score was $2.32 \pm 1.074$, with the minimum score being 0 and the maximum 5 .

Table 1 compares the parametric demographic data and some of the clinical variables between the two groups (low and high risk of OSA) by independent t-test analysis. According to Table 1, the number of children, hip circumference, wrist circumference, FBS, total cholesterol, TG, and LDL cholesterol were significantly higher in the high-risk group than the low-risk group $(P<0.05)$. Table 2 presents a comparison of the risk of OSA based on the nonparametric variables, including driver's license class, driving style, and marital status, as assessed by the chi-square test. Given the results presented in Table 2, there was a significant relationship between

Table 1. A comparison of the parametric demographic and clinical variables according to the risk of OSA

\begin{tabular}{lcccccc}
\hline \multirow{2}{*}{ Variable } & \multicolumn{2}{c}{ Risk of OSA } & & t & df & $P$ \\
\cline { 2 - 3 } & \multicolumn{2}{c}{ Low } & High & & & \\
\hline No. of children & $1.55 \pm 0.59$ & $2.98 \pm 1.16$ & -14.87 & 311.08 & $<0.01$ \\
Hip circumference (cm) & $101.55 \pm 6.60$ & $108.86 \pm 8.17$ & -10.15 & 406.14 & $<0.01$ \\
Wrist circumference (cm) & $17.88 \pm 1.05$ & $19 \pm 1.14$ & -10.56 & 426 & $<0.01$ \\
FBS (mg/dL) & $88.47 \pm 11.78$ & $98.63 \pm 23.28$ & -5.69 & 315.34 & $<0.01$ \\
Total cholesterol (mg/dL) & $180.81 \pm 38.21$ & $192.43 \pm 42.26$ & -2.98 & 426 & $<0.01$ \\
TG (mg/dL) & $154.91 \pm 56.62$ & $178.79 \pm 86.15$ & -3.38 & 368.10 & $<0.01$ \\
HDL cholesterol (mg/dL) & $38.58 \pm 8.79$ & $38.29 \pm 8.84$ & 0.34 & 426 & 0.73 \\
LDL cholesterol (mg/dL) & $111.89 \pm 31.99$ & $119.54 \pm 34.13$ & -2.37 & 421 & 0.01 \\
\hline
\end{tabular}

Values are presented as mean \pm standard deviation.

OSA, obstructive sleep apnea; FBS, fasting blood sugar; TG, triglycerides; HDL, highdensity lipoprotein; LDL, low-density lipoprotein.

Table 2. A comparison of the risk of OSA based on the nonparametric variables

\begin{tabular}{|c|c|c|c|c|c|}
\hline \multirow{2}{*}{ Variable } & \multicolumn{2}{|c|}{ Risk of OSA } & \multirow{2}{*}{$\chi^{2}$} & \multirow{2}{*}{ df } & \multirow{2}{*}{$P$} \\
\hline & Low & High & & & \\
\hline Driver's license class & & & 9.50 & 2 & 0.01 \\
\hline Class 1 & 126 & 155 & & & \\
\hline Classes 2, 3 & 88 & 59 & & & \\
\hline Driving style & & & 0.21 & 1 & 0.32 \\
\hline Transporting passenger & 46 & 50 & & & \\
\hline Heavy road vehicle & 168 & 164 & & & \\
\hline Marital status & & & 20.56 & 1 & 0.01 \\
\hline Married & 181 & 208 & & & \\
\hline Single & 33 & 6 & & & \\
\hline
\end{tabular}

OSA, obstructive sleep apnea. driver's license class and marital status and the risk of OSA $(P<0.05)$. Table 3 presents the correlations of the other demographic variables and some of the parametric clinical variables with the risk of OSA calculated by Pearson correlation analysis. According to Table 3 , the number of children, TG, total cholesterol, FBS, hip circumference, and wrist circumference had a positive and significant correlation with the risk of OSA $(P<0.05)$.

Based on the ATP III definition, MetS is indicated when three variables are out of the normal range. These variables include abdominal circumference, FBS, TG, HDL cholesterol, and blood pressure. In this study, the highest frequency $(337,78.8 \%)$ of MetS was observed in the cases with HDL cholesterol $<40 \mathrm{mg} / \mathrm{dL}$. The relationship between suffering MetS and the risk of OSA was assessed by chi-square test $(P<0.05)$; there was a significant relationship between them. In the group with the high risk of OSA, 145 drivers had MetS. More details are provided in Table 4.

To evaluate the MetS-predicting variables (except waist circumference) of sleep apnea, binary logistic regression analysis was used, as shown in Table 5. According to Table 5, MetS variables including FBS, TG, and hypertension (based on both systolic and diastolic blood pressures), but excluding HDL cholesterol, were able to predict OSA in the professional drivers $(P<0.05)$.

Table 3. The correlation of some of the parametric variables with the risk of OSA $(n=214)$

\begin{tabular}{lccc}
\hline Variable & Mean \pm SD & $r$ & $P$ \\
\hline No. of children & $2.38 \pm 1.19$ & 0.54 & 0.01 \\
HDL cholesterol (mg/dL) & $38.43 \pm 8.81$ & 0.01 & 0.43 \\
TG $(\mathrm{mg} / \mathrm{dL})$ & $166.85 \pm 73.78$ & 0.18 & 0.01 \\
Total cholesterol (mg/dL) & $186.62 \pm 40.66$ & 0.12 & 0.01 \\
FBS $(\mathrm{mg} / \mathrm{dL})$ & $93.55 \pm 19.11$ & 0.21 & 0.01 \\
Hip circumference $(\mathrm{cm})$ & $105.21 \pm 8.27$ & 0.56 & 0.01 \\
Wrist circumference $(\mathrm{cm})$ & $18.44 \pm 1.23$ & 0.56 & 0.01 \\
\hline
\end{tabular}

OSA, obstructive sleep apnea; SD, standard deviation; HDL, high-density lipoprotein; TG, triglycerides; FBS, fasting blood sugar.

Table 4. The relationship between having MetS and risk of OSA

\begin{tabular}{|c|c|c|c|c|c|}
\hline \multirow{2}{*}{$\begin{array}{c}\text { Having } \\
\text { MetS }\end{array}$} & \multicolumn{2}{|c|}{ Risk of OSA } & \multirow{2}{*}{ Total } & \multirow{2}{*}{$\chi^{2}$} & \multirow{2}{*}{$P$} \\
\hline & Low & High & & & \\
\hline No & 155 & 69 & 224 & 69.27 & $<0.01$ \\
\hline Yes & 59 & 145 & 204 & & \\
\hline
\end{tabular}

MetS, metabolic syndrome; OSA, obstructive sleep apnea. 
Table 5. The MetS-predicting variables of OSA based on the regression analysis

\begin{tabular}{lrrrrrc}
\hline Variable & B & SE & Wald & Sig & Odds ratio & $95 \%$ Cl \\
\hline FBS (mg/dL) & -1.46 & 0.26 & 30.79 & $<0.01$ & 0.23 & $0.13-0.38$ \\
TG (mg/dL) & -0.57 & 0.21 & 7.27 & $<0.01$ & 0.56 & $0.36-0.85$ \\
HDL cholesterol (mg/dL) & -0.17 & 0.26 & 0.43 & 0.50 & 0.83 & $0.49-1.41$ \\
HTN by systolic pressure $(\mathrm{mmHg})$ & 0.77 & 0.24 & 10.29 & $<0.01$ & 2.17 & $1.35-3.50$ \\
HTN by diastolic pressure $(\mathrm{mmHg})$ & 0.62 & 0.28 & 4.88 & 0.02 & 1.86 & $1.07-3.22$ \\
\hline
\end{tabular}

MetS, metabolic syndrome; OSA, obstructive sleep apnea; SE, standard error ; Sig, significance; Cl, confidence interval; FBS, fasting blood sugar; TG, triglycerides; HDL, high-density lipoprotein; HTN, hypertension.

\section{DISCUSSION}

According to the definition of MetS based on the ATP III criteria, 204 drivers (47.7\%) had MetS. In line with the present study, Lemke et al., ${ }^{30}$ in a cross-sectional study of 262 long-haul truck drivers, suggested that almost $60 \%$ of the subjects met MetS criteria; it was also shown that driving experience and sleep quality were associated with the prevalence and severity of MetS. In addition, Huang et al. ${ }^{31}$ declared that professional bus and taxi drivers showed a higher incidence of MetS than regular drivers.

Number of children, hip circumference, wrist circumference, FBS, total cholesterol, TG, and LDL cholesterol were significantly higher in the high-risk for OSA group than in the low-risk group. Also, the factors associated with OSA included driver's license class and marital status. All demographic and parametric variables that were included in the SBQ were excluded in analysis. As demonstrated, in addition to the central obesity variables (e.g., abdominal circumference, weight, and BMI), larger wrist and hip circumferences can raise the risk of OSA. A new finding is the relationship of driver's license class with the risk of OSA, which indicates that drivers of trucks more than 6 tons and passenger cars more than 26 people are at high risk of OSA, and this is not dependent on the type of vehicle. These drivers have a very important and high-risk occupation, which means more attention should be focused on them.

In a study of 1,413 freight and passenger train drivers, Gu et al. ${ }^{32}$ demonstrated that $48.43 \%$ of the drivers had poor sleep quality. Sleep quality was found to have a significant relationship with occupation type, workout type, smoking, and alcohol consumption; meanwhile, it had no relationship with education, marital status, or age. Furthermore, Shekari Soleimanloo et al. ${ }^{33}$ argued that sleeprelated accidents can be associated with little time to sleep, low sleep deprivation tolerance, and having the evolving part of the brain involved in decision-making in young drivers (18-40 years).

As expected, there was a significant relationship between having MetS and the risk of OSA. The regression analysis showed that MetS variables, including FBS, TG, hypertension (based on both systolic and diastolic blood pressures) but excluding HDL cholesterol, could predict sleep apnea in the professional drivers. Obesity (especially central obesity) is the core pathology for both MetS and OSA. Thus, to reveal the variables predicting OSA according to MetS parameters, waist circumference was excluded.

According to the results of Shayestefar et al., ${ }^{34}$ drivers with MetS suffer from more sleep disorders. Also, they hypothesize that there is a bi-directional association between sleep disorders and MetS. Vgontzas et al. ${ }^{35}$ revealed that there is considerable evidence suggesting that the MetS causes OSA, including the well-characterized role of obesity in the development of OSA, the effect of MetS on upper airway pathophysiology, the parallel prevalence of MetS and OSA across a lifetime, and emerging evidence that inflammation mediates this relationship. A study by Koo et al..$^{36}$ to clarify the relationship between sleep variables and the presence of MetS in 85 patients with OSA revealed that patients with MetS had a significantly higher Apnea-Hypopnea Index compared to patients without MetS, and Korean patients frequently had OSA with MetS. In line with this outcome, Chen ${ }^{37}$ also suggested that circadian rhythms play an overarching role in the intricate relationships among MetS, OSA, and hypertension. In addition, Bore ${ }^{38}$ studied sleeping habits and MetS and found that the metabolic results of OSAS can contribute to MetS. It was predictable that hypertension can predict the risk of OSA, but both systolic and diastolic pressures can predict the risk of OSA.

However, an interesting finding in this study is that the HDL 
cholesterol level cannot predict the risk of OSA, while others MetS variables can. Also, there was no difference in the mean level of HDL cholesterol in the two groups, and the levels were in the normal range. In contrast, Kong et al. $^{39}$ revealed in a meta-analysis study that the severity of MetS was accompanied by higher glucose and lower HDL cholesterol levels and, surprisingly, by lower TG levels. Further studies should pay more attention to this finding.

Given the higher risk of OSA in drivers, especially drivers of high risk who are transporting freight and passenger vehicles long distances with MetS, and also the importance of drivers' health both for themselves and for others using their services, preventive measures should be adopted to detect and treat MetS and OSA, such as carrying out periodic medical examinations, performing and assessing laboratory tests, and holding related training workshops.

Future interventional studies are recommended to control the MetS and OSA in drivers. The issue of MetS and sleep disorders in female drivers should also be assessed in Iran. It was not possible to investigate female drivers in this study because there are very few professional female drivers in Iran. This study was case-control; meanwhile, an interventional study could show observational results about sleep apnea.

The MetS was assessed as a disorder with a high prevalence, mortality, and morbidity. Also, drivers were assessed as a group whose health is important both for themselves and for the other people using their services. Two large groups of drivers in Shahroud were compared.

\section{CONFLICTS OF INTEREST}

The authors declare no conflict of interest.

\section{ACKNOWLEDGMENTS}

We would like to express our gratitude to all the participants in this study. This article is derived from a medical project at Shahroud University of Medical Sciences.

\section{AUTHOR CONTRIBUTIONS}

Study concept and design: MHE; acquisition of data: MHE; analysis and interpretation of data: SJ and MS; drafting of the manuscript: MS and SJ; critical revision of the manuscript: MHE and MS; statistical analysis: MS and SJ; administrative, technical, or material support: MHE and MS; and study supervision: MS.

\section{REFERENCES}

1. Ghimire A, Nagesh S, Jha N, Niraula SR, Devkota S. An epidemiological study of injury among urban population. Kathmandu Univ Med J (KUMJ) 2009;7:402-7.

2. Chandran A, Hyder AA, Peek-Asa C. The global burden of unintentional injuries and an agenda for progress. Epidemiol Rev 2010;32:110-20.

3. Alexandrescu R, O’Brien SJ, Lecky FE. A review of injury epidemiology in the UK and Europe: some methodological considerations in constructing rates. BMC Public Health 2009;9: 226.

4. Khosravi A, Aghamohamadi S, Kazemi E. Mortality profile in the Islamic Republic of Iran 2015 (20 leading cause of death by sex and age group). Tehran: Ministry of Health and Medical Education; 2015.

5. World Health Organization. Road safety: estimated number of road traffic deaths, 2013 [Internet]. Geneva: World Health Organization; 2013 [cited 2021 Mar 9]. Available from: http:// gamapserver.who.int/gho/interactive_charts/road_safety/ road_traffic_deaths/atlas.html

6. Ebrahimi MH, Sadeghi M, Dehghani M, Niiat KS. Sleep habits and road traffic accident risk for Iranian occupational drivers. Int J Occup Med Environ Health 2015;28:305-12.

7. Wu MC, Yang YC, Wu JS, Wang RH, Lu FH, Chang CJ. Short sleep duration associated with a higher prevalence of metabolic syndrome in an apparently healthy population. Prev Med 2012;55:305-9.

8. Ford ES, Giles WH, Dietz WH. Prevalence of the metabolic syndrome among US adults: findings from the third National Health and Nutrition Examination Survey. JAMA 2002;287: 356-9.

9. Shin JA, Lee JH, Lim SY, Ha HS, Kwon HS, Park YM, et al. Metabolic syndrome as a predictor of type 2 diabetes, and its clinical interpretations and usefulness. J Diabetes Investig 
2013;4:334-43.

10. National Cholesterol Education Program (NCEP) Expert Panel on Detection, Evaluation, and Treatment of High Blood Cholesterol in Adults (Adult Treatment Panel III). Third Report of the National Cholesterol Education Program (NCEP) Expert Panel on Detection, Evaluation, and Treatment of High Blood Cholesterol in Adults (Adult Treatment Panel III) final report. Circulation 2002;106:3143-421.

11. GhariPour M, Baghaei A, Boshtam M, Rabiei M. Prevalence of metabolic syndrome among the adults of central of areas of IRAN (as part of "Isfahan Healthy Heart Study"). J Birjand Univ Med Sci 2006;13:56-62.

12. Zaliūnas R, Slapikas R, Luksiene D, Slapikiene B, Statkeviciene A, Milvidaite I, et al. Prevalence of metabolic syndrome components in patients with acute coronary syndromes. Medicina (Kaunas) 2008;44:182-8.

13. Shahbazian H, Latifi SM, Jalali MT, Shahbazian H, Amani R, Nikhoo A, et al. Metabolic syndrome and its correlated factors in an urban population in South West of Iran. J Diabetes Metab Disord 2013;12:11.

14. Kaykhaei M, Hashemi M, Narouie B, Shikhzadeh A, Jahantigh M, Shirzaei E, et al. Prevalence of metabolic syndrome in adult population from Zahedan, Southeast Iran. Iran J Public Health 2012;41:70-6.

15. Wilsgaard T, Jacobsen BK. Lifestyle factors and incident metabolic syndrome: the Tromsø Study 1979-2001. Diabetes Res Clin Pract 2007;78:217-24.

16. Sari-Sarraf V, Aliasgarzadeh A, Naderali MM, Esmaeili H, Naderali EK. A combined continuous and interval aerobic training improves metabolic syndrome risk factors in men. Int J Gen Med 2015;8:203-10.

17. Santos AC, Ebrahim S, Barros H. Alcohol intake, smoking, sleeping hours, physical activity and the metabolic syndrome. Prev Med 2007;44:328-34.

18. McNicholas WT, Bonsigore MR; Management Committee of EU COST ACTION B26. Sleep apnoea as an independent risk factor for cardiovascular disease: current evidence, basic mechanisms and research priorities. Eur Respir J 2007;29: 156-78.

19. Lombardi C, Pengo MF, Parati G. Systemic hypertension in obstructive sleep apnea. J Thorac Dis 2018;10(Suppl 34): S4231-43.

20. Riha RL. Diagnostic approaches to respiratory sleep disorders. J Thorac Dis 2015;7:1373-84.

21. Mong JA, Baker FC, Mahoney MM, Paul KN, Schwartz MD, Semba K, et al. Sleep, rhythms, and the endocrine brain: influence of sex and gonadal hormones. J Neurosci 2011;31: 16107-16

22. Rosenow F, McCarthy V, Caruso AC. Sleep apnoea in endocrine diseases. J Sleep Res 1998;7:3-11.

23. Carskadon MA. Sleep in adolescents: the perfect storm. Pediatr Clin North Am 2011;58:637-47.

24. Young T, Palta M, Dempsey J, Skatrud J, Weber S, Badr S. The occurrence of sleep-disordered breathing among middle-aged adults. N Engl J Med 1993;328:1230-5.

25. Veale D, Poussin G, Benes F, Pepin JL, Levy P. Identification of quality of life concerns of patients with obstructive sleep apnoea at the time of initiation of continuous positive airway pressure: a discourse analysis. Qual Life Res 2002;11:389-99.

26. Canessa N, Castronovo V, Cappa SF, Aloia MS, Marelli S, Falini A, et al. Obstructive sleep apnea: brain structural changes and neurocognitive function before and after treatment. Am J Respir Crit Care Med 2011;183:1419-26.

27. Catalán P, Martínez A, Herrejón A, Chiner E, Martínez-García MÁ, Sancho-Chust JN, et al. Internal consistency and validity of the Spanish version of the "Quebec Sleep Questionnaire" quality-of-life questionnaire for obstructive sleep apnea. Arch Bronconeumol 2012;48:107-13.

28. Kiełbasa G, Stolarz-Skrzypek K, Pawlik A, Łątka M, Drożdż T, Olszewska M, et al. Assessment of sleep disorders among patients with hypertension and coexisting metabolic syndrome. Adv Med Sci 2016;61:261-8.

29. Sadeghniiat-Haghighi K, Montazeri A, Khajeh-Mehrizi A, Ghajarzadeh M, Alemohammad ZB, Aminian O, et al. The STOP-BANG questionnaire: reliability and validity of the Persian version in sleep clinic population. Qual Life Res 2015;24: 2025-30.

30. Lemke MK, Apostolopoulos Y, Hege A, Wideman L, Sönmez S. Work organization, sleep and metabolic syndrome among long-haul truck drivers. Occup Med (Lond) 2017;67:274-81. 
31. Huang HY, Wang W, Zhou JP, Li QL, Feng WT, Wu ZZ. Metabolic syndrome and its influencing factors in professional automobile drivers in a company. Zhonghua Lao Dong Wei Sheng Zhi Ye Bing Za Zhi 2016;34:258-61.

32. Gu GZ, Yu SF, Zhou WH, Wu H, Kang L, Chen R. Sleep quality and occupational stress relationship analysis of 1413 train drivers in a railway bureau. Zhonghua Lao Dong Wei Sheng Zhi Ye Bing Za Zhi 2017;35:514-8.

33. Shekari Soleimanloo S, White MJ, Garcia-Hansen V, Smith SS. The effects of sleep loss on young drivers' performance: a systematic review. PLoS One 2017;12:e0184002.

34. Shayestefar M, Sadeghniiat Haghighi K, Jahanfar S, Delvarianzadeh M, Nematzadeh F, Ebrahimi MH. Assessment of the relationship between metabolic syndrome and obstructive sleep apnea in male drivers of Shahroud city in 2018: a cross sectional study. BMC Public Health 2019;19:1058.
35. Vgontzas AN, Gaines J, Ryan S, McNicholas WT. CrossTalk proposal: metabolic syndrome causes sleep apnoea. J Physiol 2016;594:4687-90.

36. Koo DL, Kim HR, Nam H. Moderate to severe obstructive sleep apnea during REM sleep as a predictor of metabolic syndrome in a Korean population. Sleep Breath 2020;24: 1751-8.

37. Chen H. Circadian rhythms might be the key joint role in intricate effects among metabolic syndrome, obstructive sleep apnea, and hypertension. J Clin Hypertens (Greenwich) 2018; 20:1551-2.

38. Borel AL. Sleep apnea and sleep habits: relationships with metabolic syndrome. Nutrients 2019;11:2628.

39. Kong DL, Qin Z, Wang W, Pan Y, Kang J, Pang J. Association between obstructive sleep apnea and metabolic syndrome: a meta-analysis. Clin Invest Med 2016;39:E161-72. 